\title{
Análise de Emissões Aeronáuticas: Estudo de caso em um aeroporto da cidade do Rio de Janeiro
}

\author{
Rafael Vaz Fernandes Moreira \\ Graduado em Gestão Ambiental \\ Instituto Federal de Educação, Ciência e Tecnologia do Rio de Janeiro - IFRJ \\ \rvazfm@gmail.com \\ Simone Lorena Quiterio de Souza \\ Doutora em Ciências pela Universidade Federal do Rio de Janeiro \\ Professora da coordenação de Gestão Ambiental do Instituto Federal de Educação, \\ Ciência e Tecnologia do Rio de Janeiro - IFRJ \\ $\bowtie$ simone.quiterio@ifrj.edu.br

\section{Sergio Machado Corrêa} \\ Doutor em Físico-Química pela Universidade Federal do Rio de Janeiro \\ Professor do Departamento de Química e Ambiental - Faculdade de Tecnologia \\ da Universidade do Estado do Rio de Janeiro - UERJ - Resende \\ $\triangle$ sergio@air.pro.br
}

Recebido em 26 de março de 2018

Aceito em 24 de maio de 2018

\begin{abstract}
Resumo:
Devido ao crescimento do transporte aéreo ao longo das décadas e, consequentemente, das emissões atmosféricas por este meio, fez-se necessário o estabelecimento de estudos e normas que visam mensurar os níveis de poluentes emitidos por motores aeronáuticos. Sendo assim, este trabalho tem por objetivo estimar quantitativamente e comparar as emissões de monóxido de carbono (CO), hidrocarbonetos (HC) e óxidos de nitrogênio (NOx) da aeronave Airbus A319, série 115, durante suas operações no Aeroporto Santos Dumont, localizado na cidade do Rio de Janeiro, no período de janeiro a dezembro de 2015. Para tal, utilizou-se dados estatísticos da Agência Nacional de Aviação Civil (ANAC) e do banco de dados de emissões da Organização Internacional de Aviação Civil (ICAO). Os resultados mostraram que as emissões destes poluentes variam conforme a fase de voo da aeronave e regime de potência dos motores, que influenciam na temperatura do motor e combustão do querosene de aviação. Desta maneira, observou-se que os níveis de NOx na fase de subida inicial - na qual a aeronave, após a decolagem, ascende à um nível de segurança, livre de obstáculos -, se mantiveram, aproximadamente, 51 e 68 \% superiores, em relação as fases de decolagem e pouso, respectivamente. Em termos de CO, as emissões da fase de aproximação, mostraram-se, aproximadamente 92 e $96 \%$ superiores em relação às fases de subida inicial e decolagem, respectivamente. $O$ mesmo pode ser observado para as emissões de HC, que durante a aproximação, alcançaram valores 37 e 75 \% maiores, em relação as fases de subida inicial e decolagem, respectivamente.
\end{abstract}

Palavras-chave: Emissões, Aeronave, Qualidade do ar, Poluentes.

\section{Evaluation of aeronautical emissions: A case study of an airport at the city of Rio de Janeiro}

\begin{abstract}
:
Due to the growth of air transport over the decades, and consequently atmospheric emissions, it has become necessary to establish studies and standards to measure the levels of pollutants emitted by aeronautical engines. The aim of this work is to quantify and compare the emissions of carbon
\end{abstract}


monoxide (CO), hydrocarbons (HC) and nitrogen oxides (NOx) from the Airbus A319, 115 series, during its operations at Santos Dumont Airport, located at city of Rio de Janeiro from January to December 2015. To do so, use statistical data from the Brazilian National Civil Aviation Agency (ANAC) and the International Civil Aviation Organization (ICAO) database. The results showed that the pollutants emissions change depending on the aircraft's flight phase and engine regime, which influence the engine temperature and combustion of kerosene aviation. In this way, it was observed that the NOx levels in the climb-out phase - in which the aircraft, after take-off, rises to an unobstructed level of safety - remained approximately 51 and $68 \%$ higher in relation to the take-off and landing phases, respectively. In terms of CO, the emissions of the approach phase were approximately 92 and $96 \%$ higher in relation to the climb-out and take-off phases, respectively. The same can be observed for the HC emissions, which, during the approach, reached values 37 and $75 \%$ higher, in relation to the climb-out and take-off phases, respectively.

Keywords: Emissions, Aircraft, Air quality, Pollutants.

\section{Análisis de Emisiones Aeronáuticas: Estudio de caso en un aeropuerto de la ciudad de Río de Janeiro}

\section{Resumen:}

Debido al vertiginoso crecimiento del transporte aéreo a lo largo de las décadas, y consecuentemente, de las emisiones atmosféricas por este medio, se hizo necesario el establecimiento de estudios y normas para medir los niveles de contaminantes emitidos por motores aeronáuticos. Por lo tanto, este trabajo, tiene por objetivo estimar cuantitativamente y comparar las emisiones de monóxido de carbono (CO), hidrocarburos (HC) y óxidos de nitrógeno (NOx) de la aeronave Airbus A319, serie 115, durante sus operaciones en el Aeropuerto Santos Dumont, ciudad de Río de Janeiro, en el período de enero a diciembre de 2015. Para ello, se utilizaron datos estadísticos de la Agencia Nacional de Aviación Civil (ANAC) y del banco de datos de emisiones de la Organización Internacional de Aviación Civil (ICAO). Los resultados mostraron que las emisiones de estos contaminantes varían según la fase de vuelo de la aeronave y régimen de potencia de los motores, que influyen en la temperatura del motor y la combustión del Queroseno de Aviación. De esta manera, se observó que los niveles de NOx en la fase de ascenso inicial - en la que la aeronave, tras el despegue, asciende a un nivel de seguridad, libre de obstáculos - se mantuvieron, aproximadamente, 51 y 68 \% superiores, en relación a las fases de despegue y aterrizaje, respectivamente. En términos de CO, las emisiones de la fase de aproximación, se mostraron, aproximadamente 92 y $96 \%$ superiores en relación a las fases de ascenso inicial y despegue, respectivamente. La misma se puede observar para las emisiones de HC, que, durante la aproximación, alcanzaron los valores 37 y 75 \% superiores, en relación con las operaciones de ascenso inicial y despegue, respectivamente.

Palabras clave: Emisiones, Aeronaves, Calidad del aire, Contaminantes.

\section{INTRODUÇÃo}

A poluição atmosférica, conceituada como a ocorrência de gases e materiais particulados em níveis superiores aos naturalmente encontrados, é uma circunstância gerada e incrementada pela ação antrópica ao longo dos séculos.

Segundo Gaffney e Marley (2009), desde que o homem descobriu e começou a manipular o fogo para se aquecer e alimentar, ele teve que lidar com os subprodutos 
originados da combustão, incluindo dióxido de carbono, vapor d'agua, e uma diversidade de gases traço e aerossóis, que provocam inúmeros impactos na qualidade do ar, no clima e na saúde humana.

Recentemente, Guxens et al. (2018) estudaram a poluição atmosférica e sua relação com mudanças no desenvolvimento cerebral e cognitivo em crianças. $O$ estudo mostrou que concentrações de poluentes atmosféricos, mesmo dentro dos limites considerados seguros a saúde humana causaram alterações cerebrais. Gavinier e Nascimento (2014) avaliaram a associação entre poluentes atmosféricos e hospitalizações por acidente vascular encefálico (AVE) em indivíduos com idade igual ou superior a 50 anos, sendo possível especificar associação entre dióxido de nitrogênio e internações por AVE. Barbosa et al. (2015) investigaram a associação da poluição atmosférica em relação aos atendimentos pediátricos de emergência a portadores de anemia falciforme onde constataram entre outros, que dióxido de nitrogênio e monóxido de carbono estiveram associados a um incremento de $19 \%$ e $16,5 \%$ respectivamente, nos atendimentos totais.

Até o final da idade moderna, onde se deram os primeiros movimentos industriais, o homem contribuiu pouco a pouco com o aumento do nível de poluentes na atmosfera e consequentemente agravando os problemas de saúde das populações.

Todavia, com o advento da Segunda Revolução Industrial, ocorrida entre a segunda metade do século XIX e a primeira metade do XX, os níveis de emissões de poluentes atmosféricos foram incrementados, devido ao desenvolvimento de motores a combustão interna e externa, visto que, tais equipamentos operam pelo uso de combustíveis fósseis.

Em consonância, surgiram os primeiros projetos de aeronaves, que após anos de aprimoramento, possibilitaram a realização do transporte de pessoas e cargas por vias aéreas, de forma mais rápida e segura, principalmente, com o desfecho da segunda guerra mundial, que de acordo com Fajer (2009), em sua tese "Sistemas de investigação dos acidentes aeronáuticos da aviação geral - uma análise comparativa", tal fato, fez com que parte da indústria aeronáutica passasse a se dedicar à aviação civil.

Além da rapidez e segurança, os transportadores aéreos, à época, requeriam da indústria, aeronaves com maiores capacidade de transporte, tecnologia e autonomia de voo. Como solução a estas requisições, a indústria desenvolveu e produziu aeronaves com novas 
tecnologias de navegação, motores e aerodinâmica mais eficiente (FAJER apud CROUCH, 2008).

Os motores aeronáuticos encontram-se incluídos na categoria de motores térmicos, por utilizarem como combustíveis, substâncias derivadas da destilação do petróleo, conhecidos como Gasolina de Aviação (AVGAS) e Querosene de Aviação (JET A-1). Além disto, devem possuir qualidades que envolvem a segurança contínua do funcionamento, ausência de vibrações, facilidade de manutenção, necessitam ser duráveis, econômicos e termicamente eficientes (HOMA, 2006).

A partir da década de 1950, foram introduzidas à aviação comercial as primeiras aeronaves tracionadas por motores a jato, baseados na Terceira Lei de Newton (FAJER, 2009; HOMA, 2006).

Com o passar dos anos e o advento de novas tecnologias, tais equipamentos foram aprimorados com o intuito de melhorar a eficiência dos voos, gerando economia financeira e de combustível para os operadores, além de reduzir a emissão de poluentes e ruídos (EAGLESGATE, 2016). Os principais modelos utilizados na aviação comercial são: Turbo-Jato, Turbo-fan e Turbo-Hélice.

O funcionamento dos motores turbo- jato consiste na admissão direta do fluxo de ar pelo conjunto de compressores, que tem por finalidade, aumentar a pressão do ar admitido. Posteriormente, o ar comprimido, segue para a câmara de combustão, onde é formada a mistura ar mais combustível, e sua queima é realizada. Durante a queima, os gases são expandidos e deixam a câmara com uma velocidade maior que a do fluxo de entrada. Ao final do processo, os gases expandidos passam pelo módulo da turbina, que extrai sua energia, para acionar os compressores, através de um eixo, e outros componentes internos. Subsequentemente, esses gases, atravessam o bocal propulsor, que aumenta sua velocidade e corrige seus fluxos, aproveitando sua energia cinética para gerar a tração necessária à movimentação da aeronave (HOMA, 2006).

Mesmo sendo considerado um marco histórico para aviação e embora sua operação tenha sido postergada aos dias atuais, devido à utilização de algumas aeronaves por estes tracionadas, tais motores, com o passar do tempo, mostraram-se desvantajosos. De acordo com Homa (2006), tais equipamentos, são extremamente ruidosos, tendo sua operação vetada 
em alguns aeroportos pelo mundo. Em adição, Palharini (2014) cita que em baixas altitudes e velocidades tornam-se exímios consumidores de combustível.

A constituição básica de um turbo-fan se dá pela combinação de um motor turbo-jato e um conjunto de pás, denominadas "fan" (ventilador) (HOMA, 2006). Entretanto, possui algumas características tecnológicas que o diferenciam de seu antecessor, tornando-o mais eficiente.

Distintamente do seu antecessor, o fluxo de ar admitido por este reator, sofre um fracionamento, denominado razão "by-pass", a qual indicará a proporção entre as massas de ar que serão impulsionadas pelo "fan", denominado, fluxo de ar primário, e pelo núcleo do motor, fluxo de ar secundário. O fluxo de ar primário, cerca de $20 \%$ do ar admitido, após comprimido, será empregado na queima da mistura ar mais combustível no interior da câmara de combustão (PALHARINI, 2014). Posteriormente, a energia cinética de seus gases, acionará o conjunto de turbinas e, por consequência, através do eixo, o conjunto de compressores, o "fan" e, também, será responsável por uma pequena parcela da tração total gerada (HOMA, 2006).

Por sua vez, o fluxo de ar secundário, atravessará o núcleo do motor ao longo do "bypass", sendo utilizado para o arrefecimento e geração da maior parcela da tração, cerca de 85\% do total (PALHARINI, 2014).

A tecnologia da razão "by-pass" confere aos motores desta classe, níveis de ruído e de consumo de combustível inferiores aos turbo-jatos (HOMA, 2006), tornando estes mais econômicos e menos poluentes.

De forma análoga aos turbo-fans, os motores turbo-hélice são derivados dos turbojatos, todavia, possuem notórias diferenças estéticas e operacionais em relação a sua matriz tecnológica, apresentando, maior complexidade, maior eficiência em baixas velocidades e menor consumo de combustível (PALHARINI, 2014).

A operação do motor turbo-hélice ocorre através do processo de funcionamento básico do turbo-jato, tendo como resultado a rotação do conjunto da hélice, localizada na parte frontal do equipamento. Neste, 90 \% da força propulsora provêm da rotação da hélice, devido a grande massa de ar que pode ser movimentada, tornando-o eficaz em velocidades inferiores a 600 quilômetros por hora (HOMA, 2006). 
Entretanto, apesar de sua vertiginosa expansão e eficiência, tal modelo de transporte é um gerador de impactos ambientais, através das emissões de poluentes atmosféricos e ruídos, ambos, provindos dos motores das aeronaves. Em função disto, vários órgãos têm estabelecido normas e regulamentações com vistas à proteção do meio ambiente no âmbito das emissões atmosféricas provocadas por aeronaves.

Os principais órgãos coordenadores e reguladores da aviação civil a serem abordados neste trabalho são: a Organização Internacional de Aviação Civil (ICAO), a Agência Nacional de Aviação Civil (ANAC - BRASIL) e a Federal Aviation Administation (FAA - EUA).

A Organização Internacional de Aviação Civil é uma agência especializada da Organização das Nações Unidas (ONU), que é responsável pela elaboração de padrões, práticas operacionais e políticas que visam normatizar a aviação civil dos países signatários, sendo disposta em dezenove documentos anexos a Convenção de Chicago, destacando-se o Anexo 16 que se refere à Proteção Ambiental (ICAO, 2014).

O Anexo 16 é resultado de discussões, realizadas ao longo de décadas, despontadas a partir da percepção da ICAO acerca da responsabilidade do transporte aéreo na contribuição da poluição atmosférica. Tal documento estabelece padrões e práticas recomendadas para ventilação de combustíveis e para certificação de motores aeronáuticos turbo-jato e turbofan no âmbito das emissões de poluentes (ICAO, 2008).

Objetivando a quantificação de poluentes emitidos, este documento prescreve as metodologias e as condições necessárias à aferição de hidrocarbonetos (HC), monóxido de carbono (CO), óxidos de nitrogênio $\left(\mathrm{NO}_{\mathrm{x}}\right)$ e volume de fumaça nas operações de decolagem, subida inicial, aproximação e pouso e taxiamento, bem como, seus níveis regulatórios (ICAO, 2008). Destaca-se que a fase de subida inicial é a fase de voo pós-decolagem na qual a aeronave ascende até uma altitude segura, livre de obstáculos, onde a partir desta se inicia a elevação até a altitude requerida para o voo, ou seja, nível de cruzeiro (CASTRO et al, 2015).

Em suma, a metodologia aplicada é baseada em equações matemáticas, específicas para cada poluente, que relacionam três variáveis, sendo elas: a massa dos gases poluentes emitidos durante os procedimentos de decolagem e pouso $(D p)$, potência calculada do motor $\left(F_{\infty}\right)$ e a razão da pressão de referência $\left(\pi_{\infty}\right)($ ICAO, 2008). 
Entretanto, apesar desta norma determinar como os ensaios devem ser realizados, cada país signatário à Convenção de Chicago tem autonomia para estabelecer seus procedimentos. Contudo, segundo o Artigo 38 desta convenção, a ICAO deve ser notificada sobre quaisquer diferenças entre as regulações nacionais e as práticas internacionais (Decreto $\left.\mathrm{n}^{\mathrm{o}} 21.713,1946\right)$.

No Brasil, a Agência Nacional de Aviação Civil (ANAC) tem como um dos seus objetivos principais a regulação e a fiscalização dos ruídos e das emissões aeronáuticas (BRASIL, 2005).

A ANAC adotou dois regulamentos da autoridade norte-americana de aviação civil, "Federal Aviation Administration" (FAA), sendo eles: Regulamento Brasileiro de Aviação Civil (RBAC) nº 34 e nº 36, que tratam, respectivamente, das emissões e dos ruídos aeronáuticos.

A "Federal Aviation Administration" (FAA) é uma agência governamental dos Estados Unidos da América (EUA) tendo como propósitos a regulação da aviação civil e do transporte aéreo no país, de forma a alcançar maiores níveis de segurança, eficiência, responsabilidade ambiental e liderança global. Destaca-se que os primeiros instrumentos legais que regulavam e padronizavam o controle das emissões aeronáuticas foram idealizados pela Agência de Proteção Ambiental (EPA), durante a década de 1970 (USA, 2012).

Com o desenvolvimento de novos motores aeronáuticos, principalmente turbo-jatos e turbo-fans, ao longo das décadas seguintes, estes documentos foram constantemente atualizados tendo como resultado o Regulamento Federal de Aviação (FAR) Parte 34 (ANAC, 2013) e o Manual de Emissões da Aviação e Qualidade do Ar.

O Regulamento Federal de Aviação (FAR) Parte 34 objetiva a normatização e o controle da ventilação de combustíveis e das emissões de motores aeronáuticos à turbina. Entretanto, este adota maior rigor acerca da classificação de motores, transcendendo a generalização da ICAO, aprimorando a significância dos ensaios e dos resultados. E, o Manual de Emissões Aeronáuticas e Qualidade do Ar é um documento inteiramente elaborado pela FAA com o propósito de ser utilizado como ferramenta e recurso para auxiliar a agência e outros interessados responsáveis pelo planejamento, organização e realização de avaliações de qualidade do ar e elaboração de modelos de dispersão e inventários de emissões no tocante aos projetos relacionados à aviação (FAA, 2015). 
Sendo assim, este manual engloba todas as operações, emissoras de poluentes, relacionadas ao bom funcionamento das atividades aéreas, que incluem: a operação da aeronave, operação de veículos e equipamentos de suporte ao voo, fontes estacionárias e veículos de acesso ao aeroporto (FAA, 2015).

No que concerne aos tipos de poluentes, este instrumento, utiliza a classificação da Agência de Proteção Ambiental norte-americana (EPA) agrupando-os em três grandes classes (FAA, 2015): poluentes comuns (Dióxido de Enxofre $\left(\mathrm{SO}_{2}\right)$; Dióxido de Nitrogênio $\left(\mathrm{NO}_{2}\right)$; Material Particulado (MP) e Monóxido de Carbono (CO)); poluentes perigosos (Benzeno; Chumbo (Pb); Formaldeído; Propinaldeído; Tolueno) e gases estufa (Hexafluoreto de Enxofre $\left(\mathrm{SF}_{6}\right)$; Hidrofluorocarbonos (HFC's); Metano $\left(\mathrm{CH}_{4}\right)$; Monóxido de Carbono (CO); Óxido Nitroso $\left.\left(\mathrm{N}_{2} \mathrm{O}\right)\right)$.

Em vista disto, este trabalho tem por objetivo estimar quantitativamente e comparar as emissões de monóxido de carbono (CO), hidrocarbonetos $(\mathrm{HC})$ e óxidos de nitrogênio $\left(\mathrm{NO}_{\mathrm{x}}\right)$ da aeronave Airbus A319, série 115, durante suas operações no Aeroporto Santos Dumont. 0 foco neste modelo de aeronave se dá pela padronização da frota de A319's do operador. Os demais operadores do modelo possuem em suas frotas séries distintas, o que implica em diferentes motores e, por sua vez, distintos níveis de emissão. A divergência desses níveis, caso todas as séries do equipamento fossem englobadas, geraria erros aos resultados do trabalho. Após a análise das emissões do objeto de estudo, será realizada uma comparação com uma via de tráfego nas imediações, a fim de verificar o impacto causado pelas emissões do Airbus A319 na qualidade do ar local.

\section{MATERIAIS E MÉTODOS}

\section{Descrição do Local de Estudo}

Fundado no ano de 1936, o Aeroporto Santos Dumont, localizado na zona central do município do Rio de Janeiro, teve seu projeto idealizado pelo urbanista francês Alfred Agache, com a finalidade de suprir as demandas da época, visto que, naquele período, a cidade e capital do País não contava com nenhum aeroporto para aeronaves terrestres de 
médio porte. No ano de 1945 a estação de passageiros foi inaugurada e ao final da década de 1950, as pistas de pouso e decolagem ampliadas para as atuais dimensões (INFRAERO, 2017).

Atualmente, o Aeroporto Santos Dumont tem uma estrutura que engloba um sítio aeroportuário de $833 \mathrm{mil} \mathrm{m}^{2}$, dois terminais de passageiros de $19 \mathrm{mil} \mathrm{m}^{2}$ e um pátio de aeronaves com 21 posições, possibilitando a movimentação de, aproximadamente, 10 milhões de passageiros por ano, através das quatro companhias aéreas regulares que lá operam (INFRAERO, 2017).

No período determinado para o estudo, a média do somatório de decolagens e pousos de aeronaves comerciais foi de, aproximadamente, 8.720 por mês, tendo o Airbus A319-115, objeto deste estudo, contribuído com cerca de 752 operações por mês (ANAC, 2016).

\section{Apresentação da Aeronave Airbus A319-115}

Foi lançado no ano de 1993 pela fabricante francesa Airbus Industrie durante um evento aeronáutico ocorrido na cidade francesa de Paris, como um projeto de aeronave de médio alcance e com capacidade de transportar até 142 passageiros em classe única ou 124 em classe dupla. O Airbus A319 foi desenvolvido com a finalidade de fornecer as empresas aéreas, que já possuíam em sua frota o Airbus A320, versão principal da família, uma opção de jato menor e que melhor se adequasse a determinados aeroportos e mercados, concorrendo diretamente com os norte-americanos Boeing 737-300 e 737-700 (AIRLINERS, 2016).

De acordo com a Airbus Industrie, em seu portfólio, cerca de 1.457 aeronaves A319 foram entregues até dezembro de 2016, e deste total, 1.440 equipamentos continuam em operação ao redor do mundo. Atualmente, no Brasil, apenas duas companhias aéreas possuem o modelo base - A319 - em sua frota (AIRBUS, 2016).

No que tange às configurações de motores, a frota brasileira, bem como a mundial, não é padronizada, uma vez que tal fato implica na decisão de cada operador escolher o modelo mais adequado e eficiente ao seu sistema de voo e manutenção. Desta maneira, a companhia em questão optou por operar aeronaves que são compostas por dois motores turbo-fans CFM 56-5B7/3, produzidos pela “CFM International” (PLANESPOTTER, 2015). 


\section{Obtenção dos Dados de Operação}

Para a execução do presente estudo, foram coletadas informações sobre a configuração de motor utilizado na aeronave Airbus A319 serie 115, operados por uma companhia aérea nacional, disponíveis no "site” especializado em informações aeronáuticas "Planespotter".

Foram apurados dados estatísticos mensais referentes ao ano de 2015, das operações de companhias aéreas regulares em todo o território nacional, disponíveis em tabelas, no portfólio da Agencia Nacional de Aviação Civil (ANAC, 2016).

Por conseguinte, foram selecionados dados relativos às operações de decolagens e pousos realizados pela companhia que opera a aeronave em questão, no Aeroporto Santos Dumont.

A etapa de coleta de dados iniciou-se no portal da ANAC, com a obtenção dos dados estatísticos mensais para o ano base de estudo de 2015. Destes dados, foram escolhidos aqueles relativos às operações desejadas neste estudo, da companhia aérea em questão. Em seguida foram selecionados os dados relativos à aeronave escolhida para o estudo de caso.

\section{Obtenção dos Dados de Emissão da Aeronave}

Com o propósito de estimar as emissões aeronáuticas do equipamento no campo de estudo supracitado, tomou-se como base os dados presentes no Banco de Dados de Emissões de Aeronáuticas da Organização Internacional de Aviação Civil (ICAO), relativos à configuração de motores turbo-fan que equipam as aeronaves da série 115 operadas no Brasil e disponíveis na ANAC.

Entretanto, tais dados, fruto dos testes realizados por organismos certificados e descritos no Anexo 16 - Volume II - Emissões Aeronáuticas (ICAO, 2014) necessitaram de tratamento, conversão e readequação, através das Equações 1 a 6.

O processo para obtenção e tratamento inicia com o acesso ao banco de dados da ICAO, com subsequente tratamento dos dados desejados. 
Cálculos para Quantificação dos Dados de Emissão

As emissões por fase de vôo de Hidrocarbonetos (HC), Monóxido de Carbono (CO) e Óxidos de Nitrogênio (NOx) são relativas ao funcionamento de cada motor que compõe a aeronave e por quilograma de combustível consumido. Através das Equações 1 a 3 são calculados o valor total de poluentes emitidos, em quilogramas, pela aeronave em cada fase de voo.

$$
\begin{aligned}
& E_{H C}=\left[\left(t \cdot C C \cdot F E_{H C}\right) \cdot 10^{-3}\right] \cdot 2 \quad \text { Equação } 1 \\
& E_{C O}=\left[\left(t \cdot C C \cdot F E_{C O}\right) \cdot 10^{-3}\right] \cdot 2 \quad \text { Equação } 2 \\
& E_{N O x}=\left[\left(t \cdot C C \cdot F E_{N O x}\right) \cdot 10^{-3}\right] \cdot 2 \quad \text { Equação } 3
\end{aligned}
$$

Onde:

$\mathrm{t}$ - tempo de vôo em segundos;

CC - consumo de combustível na fase de vôo em $\mathrm{kg} \mathrm{s}^{-1}$;

FE - fator de emissão em g de poluente por kg de combustível;

Fator de $10^{-3}$ usado para conversão de g para $\mathrm{kg}$.

Constante 2 é aplicada para as duas turbinas da aeronave.

Com a intenção de obter os índices estimados de poluentes atmosféricos emitidos mensalmente, foram utilizados os dados de operações - Decolagens, Subida Inicial e Pousos da companhia aérea que opera a aeronave, segundo a ANAC.

Desta maneira, o somatório mensal de cada operação foi multiplicado pelas emissões do motor, tendo como resultado a quantidade estimada de cada poluente, conforme as Equações 4 a 6 .

$$
\begin{array}{ll}
E E_{C O}=\sum_{m \text { ês }} \text { operações } \cdot E_{C O} & \text { Equação } 4 \\
E E_{H C}=\sum_{m e ̂ s} \text { operações } \cdot E_{H C} & \text { Equação 5 } \\
E E_{N O x}=\sum_{m \text { ês }} \text { operações } \cdot E_{N O x} & \text { Equação 6 }
\end{array}
$$




\section{Seleção e Obtenção dos Dados da Via}

Como brevemente citado, a fim de se estabelecer um paralelo dos níveis de poluentes emitidos pelas aeronaves estudadas com as emissões veiculares, selecionou-se através da base de dados disponível do Inventário de Emissões Veiculares do Instituto Estadual do Ambiente do Rio de Janeiro (INEA) de 2013 (INEA, 2016), uma via de grande movimento próxima ao Aeroporto Santos Dumont e, dentre aquelas que compõem o sistema viário da área central da cidade, optou-se, em sua integral extensão, pela Avenida Presidente Antônio Carlos.

Tal escolha é justificada pelo grande movimento viário, principalmente nos horários de pico dos dias úteis, bem como, pela variabilidade de veículos que ali trafegam.

\section{Análise Estatística dos dados}

Para o estudo estatístico descritivo e multivariado dos dados obtidos foi empregada a Linguagem R (R Core Team, 2016).

\section{RESULTADOS}

Na Tabela 1 é possível observar os níveis de poluentes emitidos pelos motores da aeronave nas fases de voo selecionadas para o estudo.

Tabela 1. Níveis de emissões por aeronave em cada fase de voo pelo motor CFMI CFM56 5B7/3.

\begin{tabular}{lcccccc}
\hline \multicolumn{1}{c}{ Fase Vôo } & Potencia & Tempo & Combustível & \multicolumn{3}{c}{ Emissões Totais (kg) } \\
& & & & HC & Co & NOx \\
\hline Decolagem & $100 \%$ & $42 \mathrm{~s}$ & $95,92 \mathrm{~kg}$ & 0,002 & 0,024 & 2,069 \\
Subida Inicial & $85 \%$ & $132 \mathrm{~s}$ & $247,89 \mathrm{~kg}$ & 0,005 & 0,040 & 4,271 \\
Aprox./Pouso & $30 \%$ & $240 \mathrm{~s}$ & $151,68 \mathrm{~kg}$ & 0,008 & 0,491 & 1,342 \\
\hline
\end{tabular}

Fonte: Banco de dados da ICAO, 2013 (Elaborado pelos autores).

Na Figura 1 estão apresentados os resultados para a totalização das operações de todos os aviões escolhidos para o Aeroporto Santos Dumont para o ano de 2015. 
Figura 1. Emissões de CO, HC e NOx nas três fases de vôo ao longo do ano, respectivamente.

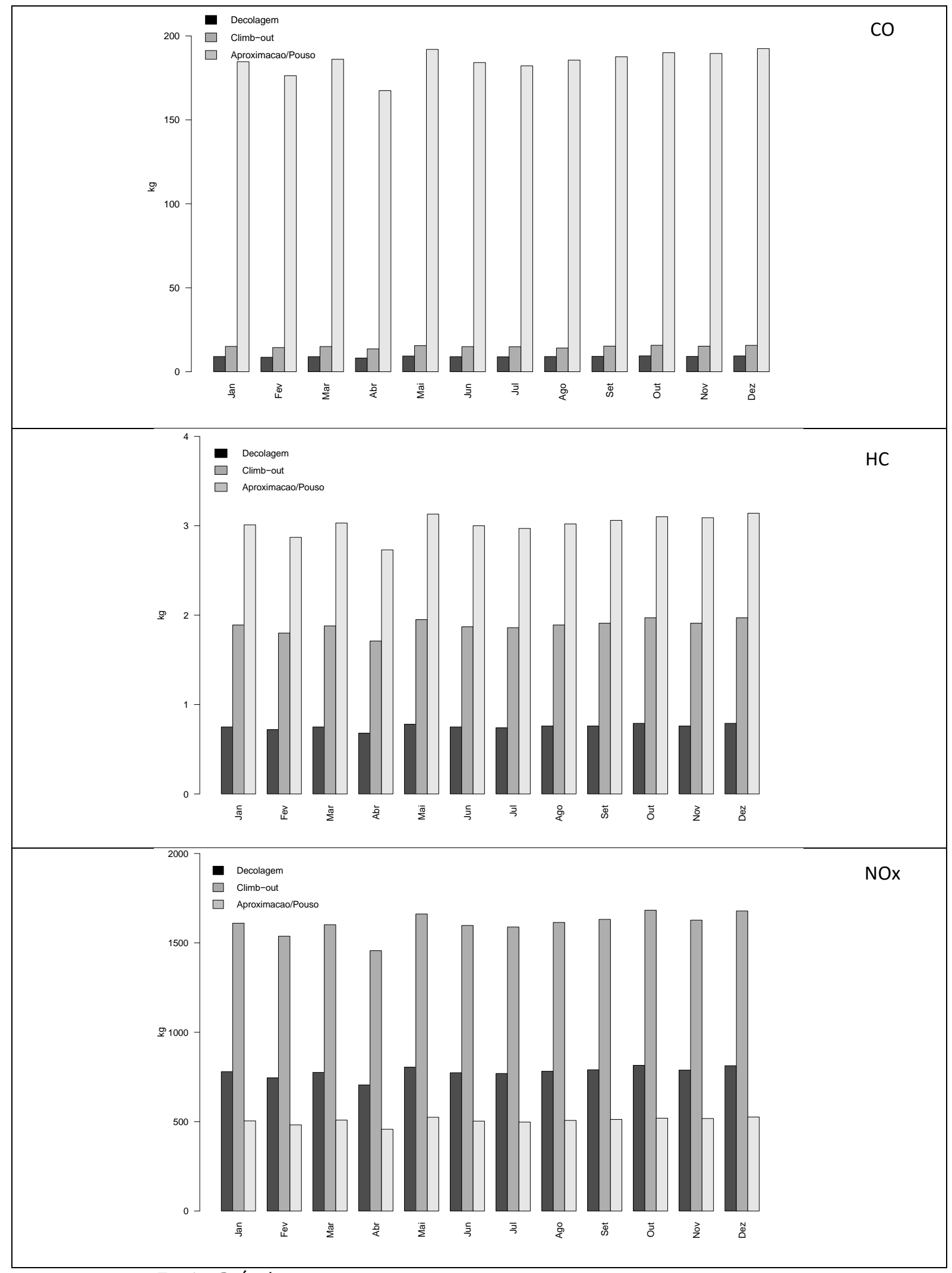

Fonte: Própria. 
A fim de avaliar todos em dados em conjunto construiu-se uma matriz de correlação, apresentada na Figura 2.

Figura 2. Matriz de correlação para as variáveis em estudo.

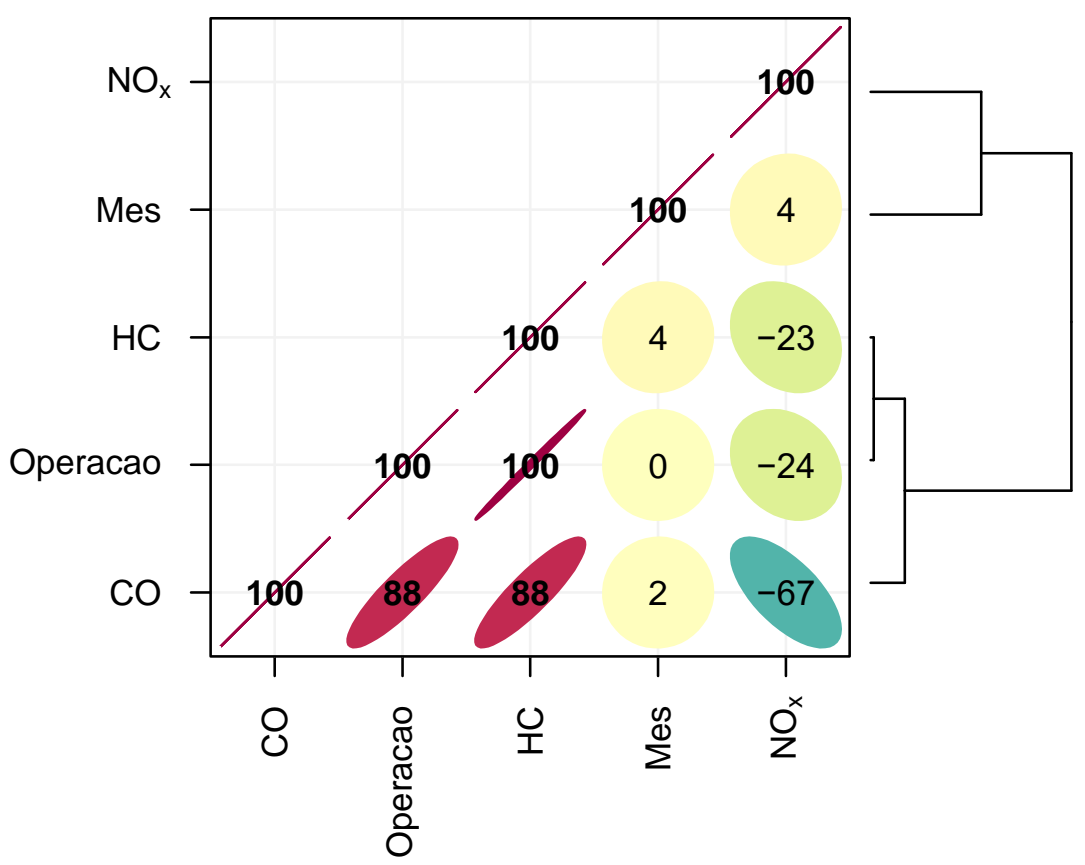

Fonte: Própria.

Utilizando a Análise de Componentes Principais (PCA) (Figura 3), foi possível avaliar o conjunto de dados sob outra ótica, observando as diferentes variáveis.

E, com o intuito de avaliar os impactos procedentes da operação do equipamento no Aeroporto Santos Dumont/RJ foi realizada uma análise comparativa das emissões geradas pelas aeronaves em relação às provindas do trafego veicular em uma via próxima ao Aeroporto, a Avenida Presidente Antônio Carlos, com base no último inventário de emissões de fontes veiculares de autoria do Instituto Estadual do Ambiente (INEA, 2016) e que possui como referência os movimentos relativos ao ano de 2013. 
Figura 3. Análise dos componentes principais (PCA) das variáveis em estudo.

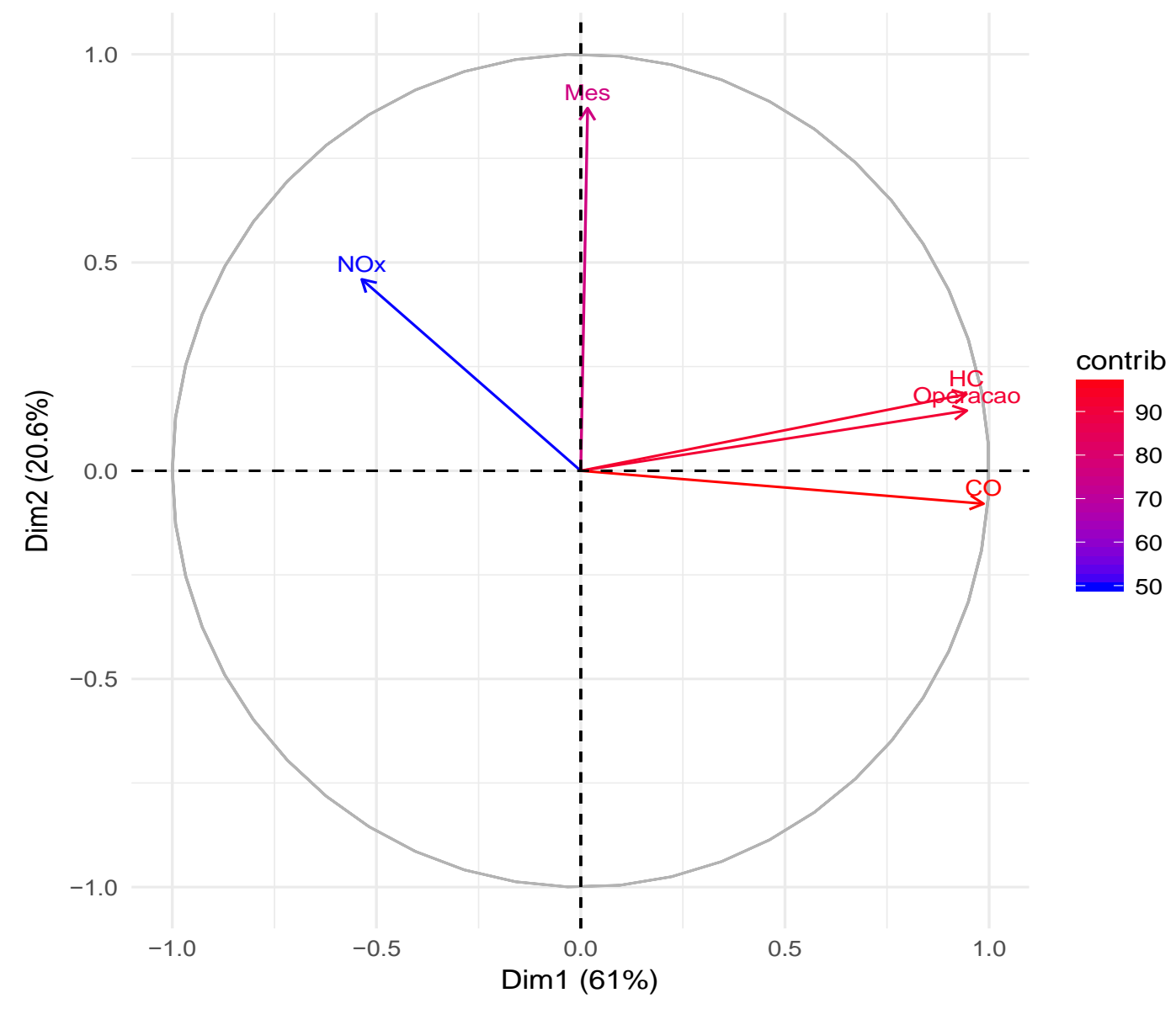

Fonte: Própria.

Desta maneira, na Tabela 2 é possível observar a média anual dos índices de trafego veicular e de poluentes emitidos na via determinada para tal comparação e os índices médios de movimentação e poluentes emitidos entre as fases de voo da aeronave.

Tabela 2. Emissões Veiculares na Avenida Presidente Antônio Carlos versus Emissões do Airbus A319-115.

\begin{tabular}{ccccc}
\hline Fonte & Unidades & HC & CO & NOx \\
& & & kg mes $^{-1}$ & \\
\hline Veículos & 4.706 .730 & 43,34 & 340,67 & 550,67 \\
Airbus A319-115 & 376 & 5,64 & 208,90 & 2.891 .10 \\
\hline Fonte: CET-Rio, 2016; ICAO, 2013; INEA, 2016 (Elaborado pelos autores).
\end{tabular}




\section{DISCUSSÃO}

Observando a Tabela 1, é importante ressaltar, que tais níveis são influenciados pelas características, de engenharia, intrínsecas de cada projeto, tal como, a quantidade de estágios nos compressores, que influenciarão na velocidade do ar primário, utilizado para a queima do combustível, a razão "by-pass" e a velocidade de saída dos gases de escape, que influenciará na potência total do motor.

Na Figura 1, verifica-se que para as emissões de CO predominam as emissões na fase de aproximação/pouso. Para as emissões de HC também a fase de aproximação/pouso é a que mais emite, sendo que a fase de subida inicial cerca de metade da aproximação/pouso. Já as emissões de NOx ocorrem predominantemente na fase de subida inicial, onde os motores operam com 100 \% de sua capacidade, gerando maiores temperaturas, favorecendo a conversão do nitrogênio atmosférico, em conjunto com o oxigênio, a NOx, segundo Schurmann et al. (2007). Ao todo, nas três fases são computadas 67,75 kg de HC, 2.506,87 kg de CO e 34.693,25 kg de NOx ao longo do ano de 2015.

Em razão do aumento de temperatura durante a fase de decolagem, e que se refletirá durante a etapa posterior, devido à necessidade de se operar em regime de alta potência, cerca de $100 \%$ da total para acelerar a aeronave (HOMA, 2006), é possível observar que as emissões de NOx durante a fase de subida inicial são aproximadamente 51 \% superiores em relação a decolagem.

Tal fato também implica nos níveis de CO apresentados, visto que motores operando em regime de alta potência, realizam o processo de combustão completa, desfavorecendo a formação deste composto (SCHURMANN et al., 2007) e tornando as emissões na fase de decolagem inferiores à de subida inicial.

Todavia, por efeito da redução de potência, os níveis de CO se tornam elevados, alcançando à média de, aproximadamente, $184,82 \mathrm{~kg}$ por ano, visto que o processo de combustão incompleta é favorecido. Desta forma, verifica-se que as emissões de CO são, aproximadamente, 21 e 12 vezes maiores na fase de aproximação e pouso em relação às fases de decolagem e subida inicial respectivamente.

No tocante as emissões anuais de HC é possível notar que durante as três fases de voo, este se manteve em níveis inferiores aos demais poluentes, alcançando nas etapas decolagem, 
subida inicial e aproximação final, valores médios de 0,75; 1,88; e 3,01 kg, respectivamente. Desta maneira, observa-se que as emissões de HC são 1,6 e 4,0 vezes maiores na fase de aproximação e pouso, em relação às de decolagem e subida inicial, respectivamente.

Portanto, é possível inferir que, no motor estudado, sua combustão está ocorrendo de maneira, próxima à completa, ou seja, a maior parcela dos HC presentes no combustível está sendo convertida em dióxido de carbono $\left(\mathrm{CO}_{2}\right)$ e água.

Analisando todos os dados em conjunto na forma de uma matriz de correlação (Figura 2), algumas observações tornam-se evidentes. Com relação ao mês de operação das aeronaves não há uma correlação com nenhuma outra variável, explicitando que as emissões são regulares ao longo do ano. Analisando-se os dados para CO, observa-se que a emissão deste poluente é altamente correlacionada $(R=0,88)$ com a fase do vôo (já elucidado antes) e com as emissões de $\mathrm{HC}(\mathrm{R}=0,88)$, indicando uma queima incompleta em determinada fase do voo, em especial na aproximação com a redução da potência. Já as emissões de CO são inversamente relacionadas com as emissões de NOx $(R=-0,67)$, indicando que quando ocorrem as maiores emissões de NOx é quando são reduzidas as emissões de CO e em menor escala de HC. A maior correlação observada é entre as emissões de $\mathrm{HC}$ e a fase do vôo $(\mathrm{R}=$ $1,00)$.

Através da ACP apresentada na Figura 3 pode-se considerar que em 81,6 \% dos dados analisados o NOx está separado dos demais dados e sua relação com as demais variáveis possui uma média significância (em torno de 50 \%). Também o mês da operação apresenta-se como uma variável de média importância (em torno de 60 \%) com relação às demais variáveis. Entretanto observa-se um grupo de variáveis coeso formado pelas emissões de CO, HC e pela fase do vôo.

Através da Tabela 2 é possível observar que as operações do equipamento estudado emitem quantidades superiores em relação aos veículos, visto que, a proporção aproximada é de, respectivamente, 12.518 veículos na via selecionada para cada operação da aeronave.

Entretanto, é possível inferir que a atividade do Airbus A319-115 no campo de estudo gera, apenas, uma pequena parcela das emissões totais, visto que, do total de operações das empresas aéreas regulares, a movimentação de decolagens e pousos deste equipamento representam, aproximadamente $7,93 \%$. 
Não obstante, é importante salientar que apesar de representar uma pequena parcela, as operações do Airbus A319-115 no Aeroporto Santos Dumont também geram poluentes que podem provocar impactos ao meio ambiente e a saúde humana, em escala local.

De maneira geral, ocorrência dos HC, CO e NOx em altas concentrações na atmosfera gera efeitos nocivos a saúde humana, dentre eles: dificuldade de respiração, fadiga e, em casos mais extremos, asfixia e morte (BAIRD e CANN, 2011).

No que concerne ao meio ambiente, quando dispostos na atmosfera os HC e NOx são responsáveis pela formação de ozônio troposférico (RODRIGUES et al., 2012).

\section{CONCLUSÕES}

Neste estudo foi possível observar a existência de uma linearidade das emissões dos distintos poluentes atmosféricos, HC, NOx e CO, em decorrência da regularidade das operações da aeronave Airbus A319 série - 115 no Aeroporto Santos Dumont, tendo esta, contribuído com, cerca de, 7,93 \% do total de operações regulares de aeronaves comerciais no ano de 2015 , no referido campo.

Além disto, foi possível observar, durante as discussões dos resultados, os fatores que favorecem a geração dos poluentes estudados, sendo eles: temperatura do motor, o consumo e combustão do querosene de aviação.

Em relação à temperatura do motor, observou-se que este fator influenciará diretamente nas emissões de NOx, tornando-as maiores na etapa de subida inicial. No caso dos $\mathrm{HC}$ e CO, os fatores que influenciam são o consumo e a combustão do querosene de aviação, apresentando níveis maiores, nas etapas de subida inicial e aproximação.

Entretanto, é importante salientar, que os dados de emissões utilizados neste estudo provêm de testes realizados em laboratórios, com motores novos e sob condições prédefinidas. Desta maneira, é possível afirmar que em determinados momentos, devido às diferenças destas condições e de manutenção dos motores das aeronaves, os níveis podem diferir daqueles descritos.

Observou-se ainda, que as emissões geradas pelo equipamento estudado são superiores em relação às veiculares em vias de grande movimento próximas ao campo de 
estudo. Certamente, tal fato ocorre devido às diferenças tecnológicas entre os motores empregados em tais meios de transporte e seus respectivos combustíveis.

Por fim, destaca-se que apesar dos avanços tecnológicos com o objetivo de assegurar um ar mais limpo, concentrações de poluentes atmosféricos continuam sendo danosas para a saúde, requerendo assim, políticas de saúde ambiental eficaz, a fim de ratificar a adoção de medidas preventivas que tenham como objetivo minimizar a degradação ambiental, e consequentemente minorar os efeitos sobre a saúde dos indivíduos.

Sendo assim, para trabalhos futuros, é expressamente recomendada a realização de aferições dos poluentes descritos, durante um período pré-determinado, a fim de obter um método de comparação com os dados da Organização Internacional de Aviação Civil (ICAO).

\section{REFERÊNCIAS BIBLIOGRÁFICAS}

AGÊNCIA NACIONAL DE AVIAÇÃo CIVIL (ANAC). Dados estatísticos do Aeroporto Santos Dumont/RJ. Disponível em: <https://www.anac.gov.br>. Acesso em: 20 Jul. 2016.

AGÊNCIA NACIONAL DE AVIAÇÃO CIVIL (ANAC). RBAC 34: Requisitos para drenagem de combustível e emissões de escapamento de aviões com motores a turbina. Brasília, 2013. Disponível em: <http://sites.unisul.br/nesc/wp-content/uploads/2017/12/RBAC34EMD04_DRENAGEM-E-EMISS\%C3\%95ESDE-GASES......pdf>. Acesso em: 20 Set. 2016.

AIRBUS. Frota mundial de aeronaves Airbus A319. Disponível em: <http://www.airbus.com/aircraftfamilies/passengeraircraft/a320family/a319/>. Acesso em: 18 Dez. 2016.

AIRLINERS. Histórico Airbus A319. Disponível em: <http://www.airliners.net/aircraft- data/airbus-a319/22> Acesso em: 18 Dez. 2016.

BAIRD, C.; CANN, M. Química Ambiental. 4ed. Porto Alegre: Bookman, 2011.

BARBOSA, S. M. M.; FARHAT, S.C.L;; MARTINS, L.C.; PEREIRA, L.A.A.; SALDIVA, P.H.N.; ZANOBETTI, A.; BRAGA, A.L.F. Poluição do ar e a saúde das crianças: a doença falciforme. Cadernos de Saúde Pública, v.31, n.2, p.265$75,2015$.

BRASIL. Decreto $\mathbf{n}^{\circ} \mathbf{2 1 . 7 1 3}$, de 27 de agosto de 1946. Promulga a Convenção sobre aviação civil internacional, concluída em Chicago a 7 de Dezembro de 1944 e firmado pelo Brasil, em Washington, a 29 de maio de 1945. Disponível em: <http://www.planalto.gov.br/ccivil_03/decreto/1930-1949/D21713.htm>. Acesso em: 21 Set. 2016.

BRASIL. Lei no 11.182, de 27 de setembro de 2005. Cria a Agência Nacional de Aviação Civil - ANAC, e dá outras providências. Disponível em: 〈http://www.planalto.gov.br/ccivil_03/_ato2004-2006/2005/Lei/L11182.htm>. Acesso em: 21 Set. 2016.

CASTRO F.M.C.; ORNELAS, J.L.C.; CONFRARIA, J.C.F.; PIEDADE, L.P.I da; CÁLÃO, M.N.; SILAVA, F.N. da. Seminário Aerospacial II. In: Trabalho Acadêmico (Mestrado Integrado em Engenharia Aerospacial). Instituto Superior 
Técnico de Lisboa, LX, $2015 . \quad$ Disponível em: <https://fenix.tecnico.ulisboa.pt/downloadFile/563568428727964/Grupo\%2008.pdf>. Acesso em: 22 Set. 2016.

COMPANHIA DE ENGENHARIA DE TRÁFEGO DO RIO DE JANEIRO (CET-Rio). Volume diário de veículos das principais vias do município do Rio de Janeiro. Disponível em: <http://www.rio.rj.gov.br/web/smtr/exibeconteudo?article-id=2801717>. Acesso em: 08 Dez. 2017.

EAGLESGATE. Evolução histórica dos motores aeronáuticos. Disponível em: <http://www.eaglesgate.com/evolhistorica.htm>. Acesso em: 19 Set. 2016.

FEDERAL AVIATION ADMINISTRATION (FAA). Aviation emissions and air quality handbook. Version 3, Update 1 W $\quad 2015 . \quad$ Disponível em: <https://www.faa.gov/regulations_policies/policy_guidance/envir_policy/airquality_handbook/media/Air_ Quality_Handbook_Appendices.pdf>. Acesso em: 25 Set. 2016.

FEDERAL AVIATION ADMINISTRATION (FAA). FAA Historical Chronology. Disponível em: <https://www.faa.gov/about/history/chronolog_history/>. Acesso em: 25 Set. 2016.

GAFFNEY, J.S; MARLEY, N.A. The Impacts of combustion emissions on air quality and climate - From coal to biofuel and beyond. Atmospheric Environment, v. 43, p. 23-36, $2009 . \quad$ DOI: https://doi.org/10.1016/j.atmosenv.2008.09.016

GAVINIER, S.; NASCIMENTO, C.F.L. Poluentes atmosféricos e internações por acidente vascular encefálico. Ambiente \& Água - An Interdisciplinary Journal of Applied Science, v.9, n.3, 2014.

GUXENS M., LUBCZYSKA M.J., MUETZEL R., DALMAU-BUENO A., JADDOE V.W., HOEK G., VAN DER LUGT A., VERHULST F.C., WHITE T., BRUNEKREEF B., TIEMEIER H., EL MARROUN H. Air pollution exposure during fetal life, brain morphology, and cognitive function in school-age children. Biological Psychiatry, 2018. DOI: https://doi.org/10.1016/j.biopsych.2018.01.016

HOMA, J. Aeronaves e Motores. 26ed. São Paulo: Asa, 2006.

INSTITUTO ESTADUAL DO AMBIENTE DO RIO DE JANEIRO (INEA). Inventário de emissões de fontes veiculares: Região Metropolitana do Rio de Janeiro. Rio de Janeiro: INEA, 2016. Disponível em: <http://www.inea.rj.gov.br/cs/groups/public/@inter_dimfis_gear/documents/document/zwew/mti2/ edisp inea0126645.pdf>. Acesso em: 08 Dez. 2017.

EMPRESA BRASILEIRA DE INFRAESTRUTURA AEROPORTUÁRIA (INFRAERO). Histórico do Aeroporto Santos Dumont/RJ. Disponível em: <http://www4.infraero.gov.br/aeroportos/aeroporto-do-rio-de-janeiro-santosdumont> Acesso: 10 Dez. 2017.

INTERNATIONAL CIVIL AVIATION ORGANIZATION (ICAO). Enviromental Protection: Volume II Aircraft Engine Emissions. Third Edition, Montreal, 2014. Disponível em: <https://www.icao.int/environmentalprotection/Documents/SGAR_2016_ETM_Vol2.pdf>. Acesso em: 25 Set. 2016.

INTERNATIONAL CIVIL AVIATION ORGANIZATION (ICAO). Engine Exhaust Emissions Data Bank Subsonic Engines: CFMI CFM56 - 5B7/3. Ohio, 2008. Disponível em: <http://www.easa.europa.eu/node/15672> Acesso em: 25 Set. 2016.

RODRIGUES, D. ANGELOTTI, F. PINHEIRO, G. GHINI, R. FERNANDES, H. Impacto do aumento da concentração de dióxido de carbono sobre o Oídio da videira. In: Workshop para mudanças climáticas e problemas fitossanitários. Jaguariúna, SP: Embrapa, 2012. Disponível em: <https://www.embrapa.br/meioambiente/busca-de-publicacoes/-/publicacao/945744/impacto-do-aumento-da-concentracao-de-dioxido-decarbono-sobre-o-oidio-da-videira>. Acesso em: 25 Out. 2016.

PALHARINI, M.J.A. Motores a Reação. 12ed. São Paulo: Bianch Pilot Training, 2014.

PLANESPOTTERS. Dados referentes à frota de Airbus A319-115 no Brasil no ano de 2015. Disponível em: <https://www.planespotters.net>. Acesso em: 20 Dez. 2016. 
R CORE TEAM 2016. R: A language and environment for statistical computing. R Foundation for Statistical Computing, Vienna, Austria. Disponível em: https://www.R-project.org/.

SCHURMANN, G. et al. The impacts of NOx, CO and VOC emissions on the air quality of Zurich Aiport, Atmospheric Environment, v. 41, p. 108 - 113, 2007. DOI: https://doi.org/10.1016/j.atmosenv.2006.07.030

UNITED STATES OF AMERICA (USA). Code of Federal Regulation, Tile 40, Part 87 - Control of Air Pollution from aircraft and aircraft engines. USA, 2012a. Disponível em: <http://www.ecfr.gov>. Acesso em: 27 Set. 2016.

UNITED STATES OF AMERICA (USA). Code of Federal Regulation, Tile 14, Part 34 - Fuel venting and exhaust emission requirements for turbine engine powered airplanes. USA, 2012b. Disponível em: <http://www.ecfr.gov>. Acesso em: 27 Set. 2016. 